\author{
Н. В. Грызунова, И. А. Киселева \\ Российский экономический университет имени Г. В. Плеханова, \\ Москва, Россия \\ К. Э. Веденьев \\ ООО «ЭТС-Энерго», Москва, Россия
}

\begin{abstract}
В настоящее время меняются концепции организации энергетического хозяйства и тарифного ценообразования. В процессе оценки силы давления санкций все соглашаются, что самый тяжелый урон наносят финансовые инструменты. Поэтому инновационную деятельность в электроэнергетическом секторе прежде всего начинают именно с финансовых инноваций. Следует также помнить и о будущих доходах стейкхолдеров и домашних хозяйств, которые планируют переориентацию своих инвестиций из нефтяного сектора в электроэнергетику. Эта тенденция активно дискутируется, хотя для России с ее запасами газа и сложившимися предпочтениями потребителей процесс смены инвестиционных предпочтений затянется. Финансовая платформа в этой отрасли пока не отличается фундаментальностью. Переходить к инновациям можно лишь после аккумулирования определенных накоплений. Например, планируются изменения элементов структуры энергетического и топливного потенциала, реформирование технико-технологических элементов инфраструктуры (чат-боты с географическими и продуктовыми приложениями, дроны, квадракоптеры, которые могут быть использованы для линейных и высотных сооружений). Также в перспективе создание новых кластеров потребителей с определенным социальным индексом. В статье авторами рассмотрены финансовые и инновационные решения для реализации инвестиционных программ в электроэнергетическом комплексе в условиях цифровизации и императивных индексов инвестирования, хотя цифровизацию называют главным антиэкологическим фактором в этом секторе экономики.

Ключевые слова: электроэнергетический сектор, инвестиционные программы, финансы, ESG-принципы.
\end{abstract}

\title{
FINANCE AND INNOVATION SOLUTIONS TO IMPLEMENT INVESTMENT PROGRAMS IN ELECTRIC-POWER COMPLEX OF THE RUSSIAN FEDERATION
}

\author{
Natalya V. Gryzunova, Irina A. Kiseleva \\ Plekhanov Russian University of Economics, Moscow, Russia \\ Kirill E. Vedenev \\ LLC "ETS-Energo", Moscow, Russia
}

Today we observe changes in concepts of organizing power - engineering industry and tariff pricing. While estimating the pressure of sanctions, everybody agrees that the worst damage is caused by finance tools. Therefore, innovation in electric-power sector is started with finance innovation. It is also necessary to bear in mind the future earnings of stakeholders and households that plan to re-orient their investment from oil sector to electric-power engineering. This trend is being discussed right now, though for Russia with its gas reserves and customer preferences the process of investment changes can be rather long. The finance platform in this industry is not fundamental yet. It is possible to start innovation only after accumulating some funds. For instance, it is planned to change elements in the structure of power and fuel potential, to reform technical and technological elements of 
infrastructure (chat-bots with geographic and product applications, drones, quadrocopters, which can be used for linear and high buildings). In the future it is planned to develop new customer clusters with certain social index. In the article the authors study finance and innovation solutions to implement innovation programs in electricpower complex in conditions of digitalization and imperative indices of investment, though digitalization is called the key anti-ecological factor in this sector.

Keywords: electric-power sector, investment programs, finance, ESG-principles.

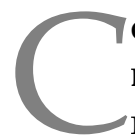

овершенствование функционирования электроэнергетики возможно на базе формирования социального капитала энергетических компаний, изменения, перепрофилирования ключевых клиентов и изменения всей системы управления персоналом. Повышение качества и надежности электроснабжения потребителей базируется на возможностях выбора, например, между электричеством, газом и дивидендами. Последовательное снижение издержек возможно лишь в условиях осуществления технологического ценового аудита, обеспечивающего необходимый контроль, рационализацию расходов на инновации, глубокое и всестороннее диагностирование и мониторинг оборудования, энергообъектов и систем управления. Технологический ценовой аудит применим и для всего технологического передела - от OEM (Original Equipment Manufacturer) до инноваций автопрома, что обеспечивает прозрачность и безопасность инвестирования. Именно этот процесс инновационного обновления заложен в Энергетической стратегии Российской Федерации на период до 2035 года. Однако эти инновации ограничиваются широкой линейкой мисселинга. Механизм реформирования требует создания и реализации долгосрочной государственной стратегии на основе интенсивной модернизации основного технологического оборудования и методов мониторинга и контроля, а также управленческих технологий с учетом смещения ассортимента стратегических ресурсов и изменения роли стратегических поставщиков.

Основная проблема энергетики сегодня состоит в том, что она разрушена. Механизм поддержки технического состояния рухнул в связи с перестройкой. Электро- энергетику стали разрушать одной из первых, поскольку это стратегическая отрасль, обеспечивающая конкурентоспособность страны.

Для отражения инновационных изменений на рынке требуются новые показатели, один из которых - экологический комплекс, формируемый $\mathrm{OOH}$ уже 20 лет и объединяющий социальное и корпоративное управление (ESG). Этот комплексный показатель (система) позиционируют как индекс бизнес-доверия, социальной и экологической нетоксичности компании. В то же время при необходимости он может выступать фактором санкционного давления, как неоднократно отмечали за последнее десятилетие. Этот индекс постепенно становится синонимом ответственного инвестирования. Многие оценили негативные последствия монополизации информационного пространства такими медиагигантами, как Thomson Reuters, что привело не только к политизации финансовой информации и прогнозов, но и к криминальному манипулированию ценами.

ESG-система сейчас активно продвигается как экологический и социальный критерий инклюзивного капитализма, но до сих пор ведется конкуренция между странами за информационно-стандартное право. В настоящее время ESG-индекс закреплен в Принципах ответственного инвестирования. Каждый год структура индекса расширяется. Сегодня он состоит уже из 17 позиций. Например, для того чтобы рассчитывать на иностранные инвестиции, организация должна соответствовать требованиям ESG-нормативов по выбросам и переработке отходов, рекультивации земель, восстановлению лесов, реализовывать программы ресурсосбереже- 
ния, энергосбережения. Среди электроэнергетических компаний наблюдается стабильный рост числа портфелей с ESGфакторами.

Длительное время экономической истории нашей страны инвестиционная политика брала за ориентир иностранные вливания. Но опыт последних десятилетий показывает слабую маневренность и низкую эффективность этих инвестиций. Поэтому стейкхолдеры стали рассматривать внутренний инвестиционный потенциал домашних хозяйств. Так, уже формируется портфель зеленых облигаций. Однако спрос на ESG-инструменты финансирования во всем мире становится все более динамичным.

До сих пор не существует единой методологии присвоения рейтинга компаниям и облигациям. ESG-рейтинг российских компаний можно посмотреть в базах RAEX и Thomson Reuters. В 2019 г. в топ-5 попали компании «Лукойл», «Татнефть», «Газпром», «Норильский никель» (несмотря на экологическую аварию), «Россети». Компании с лучшими ESG-факторами представлены в табл. 1. Безусловно, следует начать создание собственного информационного ресурса.

Та блица 1

ESG-факторы, 2020 г.

\begin{tabular}{|l|c|c|c|}
\hline \multicolumn{1}{|c|}{ Показатель } & $\begin{array}{c}\text { ПАО «Но- } \\
\text { рильский } \\
\text { никель» }\end{array}$ & $\begin{array}{c}\text { ПАО } \\
\text { «Россети» }\end{array}$ & $\begin{array}{c}\text { ПАО } \\
\text { «укойл» }\end{array}$ \\
\hline $\begin{array}{l}\text { ESG комбиниро- } \\
\text { ванный }\end{array}$ & 27,84 & 31,38 & 32,23 \\
\hline ESG-ранг & 29 & 20 & 1 \\
\hline $\begin{array}{l}\text { Оценка } \\
\text { экологического } \\
\text { компонента }\end{array}$ & 35,22 & 30,71 & 31,50 \\
\hline $\begin{array}{l}\text { Оценка социаль- } \\
\text { ного компонента }\end{array}$ & 28,83 & 33,28 & 38,55 \\
\hline $\begin{array}{l}\text { Оценка } \\
\text { управленческого } \\
\text { компонента }\end{array}$ & 47,54 & 44,92 & 34,38 \\
\hline $\begin{array}{l}\text { ЕSG-показатель } \\
\text { противоречий }\end{array}$ & 100,00 & 100,00 & 100 \\
\hline
\end{tabular}

* Составлено по данным Thomson Reuters и Агентства RAEX.

Россия планирует внести существенный вклад в низкоуглеродную траекторию развития экономики мира и противодействие изменениям климата [4] в соответствии со своей новой энергетической политикой [1]. Достижение подобной цели невозможно без изменения номенклатуры показателей энергоэффективности и контроля. Говорят, что легче перенести кладбище, чем ввести в обращение новую отчетность. Тем не менее смена системы отчетности необходима, если Россия планирует использовать свой рейтинг поставщика энергоресурсов и играть соответствующую роль в ESG-политике, а не следовать чужим разработкам. Пассивное поведение на финансовом рынке несет макроэкономические угрозы для страны.

ESG-система может быть включена в новую энергетическую политику, и пока возможны кардинальные преобразования поведения и инвестирования энергетических компаний. В настоящее время администрирование данного сектора не будет слишком проблематичным, поскольку основная доля акций принадлежит стратегическим инвесторам или институциональным организациям. Финансовая власть находится у стратегических инвесторов, что, в частности доказывает показатель free float (рисунок). Как можно видеть, уровень управляемости компаний энергетического сектора высокий.

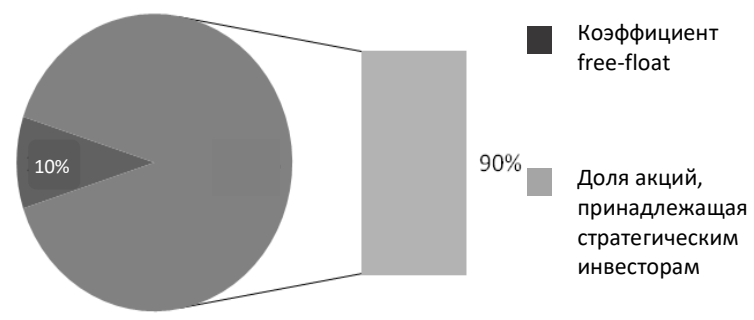

Рис. Коэффициент free float в энергетическом секторе

Составлено по данным Thomson Reuters.

Согласно стратегии развития электроэнергетики до 2035 г., государство готово расширять жесткие ограничения в производстве с учетом факторов ресурсосбережения в ракурсе основных целей стратегии: эффективность, инвестиции в новые акти- 
вы, расширение сферы услуг и цифрового потенциала по всем переделам отрасли. Возможно, это изменит уровень парниковой угрозы и улучшит экологическую обстановку и качество жизни людей [2].

Планируется последовательное сокращение энергоемкости отрасли. К 2035 г. уровень этого показателя должен быть в пределах 1,18-1,25 Нm (в том числе за счет расширения использования инновационных транспортных технологий, например, беспилотных летательных аппаратов, электрификации железнодорожного транспорта и распространения электромобилей) [6; 11]. Постепенно на рынке энергетики проявилась триада лидеров - Россия, Китай и Индия. От этих стран и Австралийского Союза будет зависеть мировой рынок угля.

Важным структурным изменением мировой энергетики должен стать рост КПД ресурсов в электроэнергетике в потреблении примерно на 20-25\% к 2040 г. и рост объема первичных энергетических ресурсов. Ожидается, что более $40 \%$ указанного прироста обеспечат неуглеродные ресурсы [5; 7].

К 2035 г. ожидается реформирование тарифного ценообразования, а также постепенная ликвидация перекрестного субсидирования поставок газа в различные субъекты Российской Федерации, что позволит реализовать кластеризацию энергетических организаций и дифференциацию потребителей. Посредством изменения системы тарифов планируется сокращение стоимости услуг ЖКХ и одновременный рост прибыли энергетических компаний.

В настоящее время отмечаются перспективы газификации Российской Федерации по сравнению с международной торговлей газом. Российские потребители предпочитают газ, а не электричество. С установлением предельного уровня цены с применением модели альтернативной котельной (AK), учитывающей региональные особенности, газификация даст мощную экономию по оплате услуг ЖКХ, что повысит качество жизни населения. Сейчас международные проекты саботируются, что приносит дополнительные убытки бюджету. Следовательно, следует сконцентрировать усилия на внутренних инвестициях.

Согласно бюджетным планам налоговые ставки, величина и модели тарифов будут неизменны в течение минимум пяти лет, и электроэнергетика превратится в большой кластер со специализированными центрами перевалки и торговли. Цифровизация отрасли предполагает полный переход от оперативно-диспетчерского на автоматическое дистанционное управление режимными объектами, прежде всего в Единой энергетической системе России $[8 ; 9]$.

Согласно стратегии развития электроэнергетики до 2035 г., каждый локальный рынок будет иметь персонализированную модель инвестирования и схемы теплоснабжения [4; 7].

Основные положения программы инновационного интеллектуально-технологического развития отечественной электроэнергетики до 2035 г. заключаются в следующем:

1. Создание цифровой платформы управления трафиком энергетических компаний. Цифровизация на первом этапе до 2024 г. предполагает поиск пилотных проектов. Цифровизация энергетики - это инструмент оптимизации управления функционированием энергосистемы, который способствует отбору проектов и внедрению систем мониторинга, прогнозирования и настраивания.

2. Широкое и глубокое диагностирование потребностей, расширение режимов и тарифных моделей.

3. Создание к 2035 г. отраслевых центров компетенций по приоритетным направлениям технологического развития. Предполагается, что инновационное оборудование изменит структуру ресурсной базы и тип испытательных полигонов.

4. Построение модели цифровой подстанции и сети. 
5. Повышение энергоэффективности и энергосбережения.

6. Цифровое проектирование электроэнергии.

7. Управление надежностью и активами, удаленное управление и безопасность.

8. Использование композитных материалов [9; 13].

Подобные преобразования потребуют значительных инвестиций и постоянного контроля риска дефолта и банкротства с использованием смарт-моделей. Каждая инвестиционная программа в энергетике включает в себя десятки тысяч проектов, в связи с чем прогнозирование дефолта является неотъемлемой частью программ.

В табл. 2 представлены модели прогнозирования вероятности дефолта по репрезентативным энергокомпаниям.

Модели оценки дефолта энергетических компаний

\begin{tabular}{|c|c|c|c|c|c|c|c|}
\hline \multirow[b]{2}{*}{ Название компании } & \multirow[b]{2}{*}{$\begin{array}{l}\text { Оцен- } \\
\text { ка мо- } \\
\text { дели }\end{array}$} & \multirow[b]{2}{*}{$\begin{array}{c}\text { Веро- } \\
\text { ят- } \\
\text { ность } \\
\text { дефол- } \\
\text { та, \% }\end{array}$} & \multirow{2}{*}{$\begin{array}{c}\text { Подра- } \\
\text { зуме- } \\
\text { вае- } \\
\text { мый } \\
\text { рей- } \\
\text { тинг } \\
\text { модели }\end{array}$} & \multirow[b]{2}{*}{$\begin{array}{l}\text { Агентство } \\
\text { S \& P/ } \\
\text { Moody's }\end{array}$} & \multicolumn{3}{|c|}{ Баллы компонентов } \\
\hline & & & & & $\begin{array}{l}\text { Струк- } \\
\text { турная } \\
\text { модель }\end{array}$ & $\begin{array}{c}\text { Модель ин- } \\
\text { теллектуаль- } \\
\text { ных коэф- } \\
\text { фициентов }\end{array}$ & $\begin{array}{c}\text { Модель } \\
\text { интеллек- } \\
\text { туального } \\
\text { анализа } \\
\text { текста } \\
\end{array}$ \\
\hline ПАО «Россети» & 24 & 0,12 & BBB & BBB- / Baa3 & 22 & 28 & 38 \\
\hline $\begin{array}{l}\text { ПАО «Федеральная } \\
\text { гидрогенерирующая } \\
\text { компания "РусГидро"» }\end{array}$ & 81 & 0,04 & AA- & BBB- / Baа3 & 81 & 69 & 21 \\
\hline $\begin{array}{l}\text { Аэрофлот - ПАО } \\
\text { «Российские авиали- } \\
\text { нии» }\end{array}$ & 10 & 0,21 & $\mathrm{BB}+$ & -- / -- & 3 & 13 & 24 \\
\hline ФСК ЕЭС ПАО & 33 & 0,10 & $\mathrm{BBB}+$ & BBB- / Baa3 & 83 & 65 & 8 \\
\hline ПАО «Глобалтранс» & 90 & 0,05 & $A+$ & $--/$-- & 79 & 73 & 33 \\
\hline ПАО «Интер РАО» & 79 & 0,04 & $\mathrm{~A}+$ & -- / Baa3 & 85 & 67 & 13 \\
\hline Enel Americas SA & 21 & 0,13 & BBB & BBB / -- & 25 & 46 & 30 \\
\hline $\begin{array}{l}\text { PGE Polska Grupa } \\
\text { Energetyczna SA }\end{array}$ & 23 & 0,13 & $\mathrm{BBB}$ & $--/--$ & 8 & 19 & 26 \\
\hline Медиана & 45 & 0,10 & $\mathrm{BBB}+$ & B- / B3 & 48 & 48 & 24 \\
\hline
\end{tabular}

* Составлено по данным Thomson Reuters.

Антикризисный анализ должен осуществляться в рамках среднеотраслевых показателей. Возможны различные формы привлечения финансовых ресурсов в электроэнергетику:

- капитальные вложения в соответствии с установленными критериями и с участием государства;

- фондовые накопления;

- прямые инвестиции;

- выпуск дополнительных акций (зеленых облигаций);

- кредитные ресурсы;

- прямые иностранные инвестиции;
- лизинговые схемы и пр.

Инновационная модель предполагает тесное взаимодействие планирующих и эксплуатирующих субъектов отрасли и активное освоение и использование научных результатов. Очевидно, в электроэнергетике должна быть создана экосистема, аналогичная той, что формируется сейчас для кредитных организаций Центрального банка Российской Федерации.

Для реализации стратегии инновационного развития нужна национальная программа инновационно-интеллектуального развития электроэнергетики России. 
Разработка такой программы должна осуществляться на научно обоснованных методологических принципах, определяющих максимально целесообразное выполнение стратегических целей. Основная задача состоит в значительном повышении надежности, безотказности, долговечности и безопасности электроснабжения.

В настоящее время необходимы усилия по восстановлению работ в рамках национальной интеллектуально-инновационной системы, остановленных в годы бюджетных дефицитов, а также по созданию новых тем и направлений с учетом экологических вызовов времени. Современная разработанная стратегия развития отрасли ставит перед собой цель - сменить технологический уклад. Разработанные правила [9; 12] определяют порядок отбора и утверждения инвестиционных программ субъектов электроэнергетики, соответствующих критериям, утвержденным Постановлением Правительства Российской Федерации от 1 декабря 2009 г. № 977 «Об инвестиционных программах субъектов электроэнергетики»:

а) организация центра управления единой национальной электрической сетью (экосистема);

б) кластеризация сетевых организаций;

в) создание системного оператора Единой энергетической системы России;

г) определение функционала оптовой генерирующей компании;

д) идентификация субъектов электроэнергетики, осуществляющих производство электрической энергии и (или) оказывающих услуги по передаче электрической энергии, прямое или косвенное владение долей в уставном капитале которых составляет не менее 20\% плюс одна голосующая акция в рамках компетенции оптовой гидрогенерирующей компании [9].

В последнее время в связи с цифровизацией и распространением концепций экосистем развернулись дискуссии по вопросу распределения имущественных прав и титулов собственности между государством или субъектами Федерации, муниципаль- ными образованиями и менеджментом энергетических компаний в отношении цифровых бизнес-моделей. Международные организации ОЭСР, ООН и ЕС ставят вопрос о поддержании необходимого уровня конкуренции в отрасли для предотвращения угрозы роста тарифов для населения.

Продуктовая линейка энергетических компаний кардинально меняется, а также меняется время хранения продукции энергетических компаний. Раньше считалось, что невозможность ее хранения и складирования определяет специфику этой отрасли экономики. В настоящее время благодаря цифровизации многие ограничения распределения и хранения продукции энергетических компаний преодолены. Необходимо переосмысление классических правил распределения доходов, определения внешних сил, которые могут помочь производителю сгенерировать правильное решение в рамках двусторонних тарифных и налоговых соглашений между институциональными образованиями и энергетическими компаниями.

Все чаще вспоминают статью В. И. Ленина «Империализм как высшая стадия капитализма» [10], в которой автор пророчески описывает возможный прессинг со стороны банков и манипулирование клиентами, навязывание им условий расчета, тарифов, бизнес-схем. Такой же точки зрения придерживается Э. Набиуллина. Она согласна, что за экосистемами будущее и они будут создавать новые возможности для бизнеса и потребителей, но эти преимущества будут перекрыты и уже перекрываются угрозами ограничения конкуренции.

А. Бузгалин [3] также предупреждает о диктате монополий на основе технологий big data. А. Денисов в своей работе [6] приводит примеры маркетингового манипулирования ценами на основе знания величины персональных доходов. Поскольку электроэнергетика на основе технологий big data проектирует инфраструктуру для кластеризованных пользователей, в кла- 
стере будут действовать персонифицированные тарифные модели.

В нашей стране растет недовольство чрезмерной эскалацией тарифов, хотя министр энергетики Российской Федерации Н. Г. Шульгинов полагает, что экосистема для потребителей электроэнергетики будет ограничивать рост тарифов и даже их снижение, но вряд ли в это можно поверить.

Н. Г. Шульгинов определил правила реализации инвестиционных проектов в период, на который разрабатывается инвестиционная программа (на 10 лет) [13], в частности, он отметил неизменность многих нормативов и налогов. Подобная практика уже используется, но эскалацию цен и тарифов это не останавливает.

В отрасли планируются инвестиции в сооружения, модификацию и техническое перевооружение объектов основных средств или нематериальных активов и разработка новых бизнес-схем в целях получения прибыли, например, модель партнерской инфраструктуры. Такие партнерские коллаборации строятся на основе верификации конкурентных преимуществ контрагентов, эффективных проектов и технологий при одновременно создаваемой подушке безопасности от макроэкономических и финансовых рисков.

В частности, в последнее время апробируют концепцию Smart Grid, которую используют для сетевых компаний и экосистем. Smart Grid базируется на теории графов, а для оценки эффективности в качестве критериев выступают операционные расходы, стоимость капитала, надежность обслуживания, предиктивная аналитика и др.

Модель графа в формализованном виде можно представить следующим образом [3. - C. 18]:

$$
F=\{N, m l, R), R=(A, B, U),
$$

где $N$ - уровень графа или мобильная диспетчерская;

$m l$ - паспортизация активов (позиции, с которых начинается инновационный процесс);

$R$ - вектор фактора времени, датчики, фиксирующие этапы инновационного процесса развития;

A - уровень и дифференциация результатов;

B - количество этапов цепочки стоимости;

$U$ - результаты-задания, чат-боты.

В результате поэтапных действий, определенных А. П. Балакиным [2], решается задача разработки инструментов оценки ожидаемой эффективности инновации на каждом участке графа и применения адаптивных элементов сетей в соответствии с концепцией Smart Grid, в том числе с использованием аппарата регулирования тарифов для инвестирования RAB (Regulatory Asset Base). В рамках концепции RAB, которая постепенно распространяется в энергетической отрасли, разрабатываются математические модели, финансовые инструменты, формируются ценовые, тарифные и налоговые соглашения.

Новая стратегия развития отрасли должна изменить архитектуру информационной системы управления инновациями в электросетевом хозяйстве и распределение титулов собственности для обеспечения имущественной безопасности и создания условий накопления капитала. Для управления инвестиционной деятельностью по-прежнему будет использоваться RAB. Подход на основе инвестиционных критериев позволит расширить инструменты оценки и системы ограничений, что важно для контроля инвестиционных потоков и деятельности сетевых компаний. В связи с этим выбор методики оценки проектов с учетом всех рисков позволит более взвешенно выбирать долгосрочные инвестиционные и инновационные проекты для реализации. 
Список литературы

1. Афанасъељ С. Новая энергетическая политика РФ: модернизация НПЗ, снижение налогов для всего ТЭК и альтернативные котельные. - URL: https://realnoevremya.ru/ articles/177417-novaya-energeticheskaya-politika-rf-modernizaciya-npz-snizhenie-nalogovdlya-vsego-tek-i-alternativnye-kotelnye

2. Балакин А. П. Инструменты повышения экономической эффективности инноваций в электросетевом комплексе на основе применения адаптивных элементов сетей : автореф. дис. ... канд. экон. наук. - Смоленск, 2015.

3. Бузгалин А. В., Колганов А. И. Глобальный капитал. - 2-е изд. - М. : Едиториал УРСС, 2007.

4. Булатенко М. А., Тульчинская Я. И. Состояние и направления развития теории экономики и управления электроэнергетическим комплексом России // Экономика и управление народным хозяйством. - 2013. - № 2. - С. 52-67.

5. Дементьељ В. Е., Светлов Н. М. Эффект стратегического подхода при динамическом ценообразовании на сетевые блага // Экономика и математические методы. - 2020. T. 56. - № 2. - С. 20-31.

6. Денисов А. С. Энергетики и механики Водоканала произвели техперевооружение насосных станщий Сочи. - URL: https://www.mup-vodokanal-sochi.ru/press/news/1526energetiki-i-mekhaniki-vodokanala-proizveli-tekhperevooruzhenie-nasosnykh-stantsij-sochi

7. Иванов Т. В., Иванов С. Н., Логинов Е. Л., Наумов Э. Б. Интеллектуальная электроэнергетика: стратегический тренд конкурентоспособности России в XXI веке : монография. М. : ООО «Издательство "Спутник+"», 2012.

8. Корсунов П. П. Методический инструментарий оценки и планирования конкурентоспособности топливно-энергетических предприятий : дис. ... канд. экон. наук. - Екатеринбург, 2017.

9. Куценко Д. И., Петроченко М. В., Набока А. А. Методики проведения технологического и ценового аудита инвестищионно-строительного проектов // AlfaBuild. - 2019. № 3 (10). - С. 23-35.

10. Ленин В. И. Империализм как высшая стадия капитализма. - Public Domain, 1916.

11. Муханова Д. Ю., Елохова И. В. Оценка эффективности инновационных проектов сетевых компаний электроэнергетики в условиях предстоящей цифровизации // Социально-экономические науки. - 2019. - № 2. - С. 127-134.

12. Окороков Р. В. Теория и методология управления финансовой устойчивостью электроэнергетических компаний : автореф. дис. ... д-ра экон. наук. - Иваново, 2006.

13. Соломенников С. И., Никифорова Н. М. Анализ факторов, влияющих на техникоэкономические показатели инвестиционного проекта // Фотинские чтения. - 2014. № 1. - С. 171-177.

\section{References}

1. Afanasev S. Novaya energeticheskaya politika RF: modernizatsiya NPZ, snizhenie nalogov dlya vsego TEK i alternativnye kotelnye [New Energy Policy of the Russian Federation: Modernization of Refineries, Tax Cuts for the Entire Fuel and Energy Complex and Alternative Boiler Houses]. (In Russ.). Available at: https://realnoevremya.ru/articles/ 
177417-novaya-energeticheskaya-politika-rf-modernizaciya-npz-snizhenie-nalogov-dlya-vsegotek-i-alternativnye-kotelnye

2. Balakin A. P. Instrumenty povysheniya ekonomicheskoy effektivnosti innovatsiy v elektrosetevom komplekse na osnove primeneniya adaptivnykh elementov setey. Avtoref. dis. kand. ekon. nauk [Tools for Increasing the Economic Efficiency of Innovations in the Power Grid Complex Based on the Use of Adaptive Network Elements. PhD econ. sci. abstract diss.]. Smolensk, 2015. (In Russ.).

3. Buzgalin A. V., Kolganov A. I. Globalnyy capital [Global Capital]. 2nd edited. Moscow, Editorial URSS, 2007. (In Russ.).

4. Bulatenko M. A., Tulchinskaya Ya. I. Sostoyanie i napravleniya razvitiya teorii ekonomiki i upravleniya elektroenergeticheskim kompleksom Rossii [State and Development Directions of the Theory of Economics and Management of the Electric Power Complex of Russia]. Ekonomika $i$ upravlenie narodnym khozyaystvom [Economics and Management of the National Economy], 2013, No. 2, pp. 52-67. (In Russ.).

5. Dementev V. E., Svetlov N. M. Effekt strategicheskogo podkhoda pri dinamicheskom tsenoobrazovanii na setevye blaga [The Effect of the Strategic Approach in Dynamic Pricing on Network Goods]. Ekonomika i matematicheskie metody [Economics and Mathematical Methods], 2020, Vol. 56, No. 2, pp. 20-31. (In Russ.).

6. Denisov A. S. Energetiki i mekhaniki Vodokanala proizveli tekhperevooruzhenie nasosnykh stantsiy Sochi [Power engineers and mechanics of Vodokanal carried out technical re-equipment of pumping stations in Sochi]. (In Russ.). Available at: https://www.mupvodokanal-sochi.ru/press/news/1526-energetiki-i-mekhaniki-vodokanala-proizvelitekhperevooruzhenie-nasosnykh-stantsij-sochi

7. Ivanov T. V., Ivanov S. N., Loginov E. L., Naumov E. B. Intellektualnaya elektroenergetika: strategicheskiy trend konkurentosposobnosti Rossii $\mathrm{v}$ XXI veke, monografiya [Intelligent Power Industry: Strategic Trend of Russia's Competitiveness in the XXI Century, monograph]. Moscow, OOO «Izdatelstvo "Sputnik+"», 2012. (In Russ.).

8. Korsunov P. P. Metodicheskiy instrumentariy otsenki i planirovaniya konkurentosposobnosti toplivno-energeticheskikh predpriyatiy. Dis. kand. ekon. nauk [Methodological Tools for Assessing and Planning the Competitiveness of Fuel and Energy Enterprises. PhD econ. sci. diss.]. Ekaterinburg, 2017. (In Russ.).

9. Kutsenko D. I., Petrochenko M. V., Naboka A. A. Metodiki provedeniya tekhnologicheskogo i tsenovogo audita investitsionno-stroitelnogo proektov [Techniques for Conducting a Technological and Price Audit of Investment and Construction Projects]. AlfaBuild, 2019, No. 3 (10), pp. 23-35. (In Russ.).

10. Lenin V. I. Imperializm kak vysshaya stadiya kapitalizma [Imperialism as the Highest Stage of Capitalism]. Public Domain, 1916. (In Russ.).

11. Mukhanova D. Yu., Elokhova I. V. Otsenka effektivnosti innovatsionnykh proektov setevykh kompaniy elektroenergetiki v usloviyakh predstoyashchey tsifrovizatsii [Evaluation of the Effectiveness of Innovative Projects of Grid Companies of the Electric Power Industry in the Context of the Upcoming Digitalization]. Sotsialno-ekonomicheskie nauki [Socio-Economic Sciences], 2019, No. 2, pp. 127-134. (In Russ.).

12. Okorokov R. V. Teoriya i metodologiya upravleniya finansovoy ustoychivostyu elektroenergeticheskikh kompaniy. Avtoref. diss. dokt. ekon. nauk [Theory and Methodology for Managing the Financial Stability of Electric Power Companies. Dr. econ. sci. diss.]. Ivanovo, 2006. (In Russ.). 
13. Solomennikov S. I., Nikiforova N. M. Analiz faktorov, vliyayushchikh na tekhnikoekonomicheskie pokazateli investitsionnogo proekta [Analysis of the Factors Affecting the Technical and Economic Indicators of the Investment Project]. Fotinskie chteniya [Fotinskie Readings], 2014, No. 1, pp. 171-177. (In Russ.).

\section{Сведения об авторах}

Наталья Владимировна Грызунова

доктор экономических наук,

профессор, профессор кафедры

финансового менеджмента

РЭУ им. Г. В. Плеханова.

Адрес: ФГБОУ ВО «Российский экономический университет имени Г. В. Плеханова», 117997,

Москва, Стремянный пер., д. 36.

E-mail: Gryzunova.NV@rea.ru

\section{Кирилл Эдуардович Веденьев}

заместитель генерального директора

ООО «ЭТС-Энерго».

Адрес: ООО «ЭТС-Энерго»,

115533, Москва,

проспект Андропова, д. 2.

E-mail: k.vedenyev@gmail.com

\section{Ирина Анатольевна Киселева}

доктор экономических наук,

профессор кафедры математических методов

в экономике РЭУ им. Г. В. Плеханова.

Адрес: ФГБОУ ВО «Российский экономический университет имени Г. В. Плеханова», 117997,

Москва, Стремянный пер., д. 36.

E-mail: kiseleva.iran@rea.ru

\section{Information about the authors}

Natalya V. Gryzunova

Doctor of Economics, Professor,

Professor of the Department

for Financial Management

of the PRUE.

Address: Plekhanov Russian University

of Economics, 36 Stremyanny Lane, Moscow, 117997, Russian Federation.

E-mail: Gryzunova.NV@rea.ru

\section{Kirill E. Vedenev}

Deputy General Director

of the LLC "ETS-Energo".

Address: LLC "ETS-Energo",

2 Andropov Avenue,

Moscow, 115533, Russian Federation.

E-mail: k.vedenyev@gmail.com

\section{Irina A. Kiseleva}

Doctor of Economics, Professor

of the Department for Mathematical Methods

in Economics of the PRUE .

Address: Plekhanov Russian University

of Economics, 36 Stremyanny Lane,

Moscow, 117997, Russian Federation.

E-mail: kiseleva.iran@rea.ru 